\title{
Fire Test on a Non-heat-resistant Fireproof Glass with Down-flowing Water Film
}

\author{
CHAN-WEI WU ${ }^{1}$, TA-HUI LIN ${ }^{1}$, MING-YUAN LEI ${ }^{2}$, TIEN-HSU CHUNG ${ }^{3}$, \\ CHIEN-CHANG HUANG ${ }^{4}$, and WEI-TANG $\mathrm{CHIANG}^{4}$ \\ ${ }^{1}$ Department of Mechanical Engineering \\ National Cheng Kung University \\ Taiwan, ROC \\ ${ }^{2}$ Architecture and Building Research Institute \\ Ministry of Interior \\ Taiwan, ROC \\ ${ }^{3}$ Safety Technology Co., Ltd. \\ Taiwan, ROC \\ ${ }^{4}$ Center for Environmental \\ Safety and Health Technology Development \\ Industrial Technology Research Institute \\ Taiwan, ROC
}

\begin{abstract}
The purpose of this study is to investigate the effects of a water film on the heat-resistant property associated with the insulation of a fireproof glass. The evaporative latent heat of water film could be used to protect the glass of the building from melting or breaking as a fire occurs. In the experiment, the glass panes were fire-tested up to $1000^{\circ} \mathrm{C}$ by using a standard testing furnace for doors and windows. Results showed that the application of the water film on the glass pane could effectively resist the intensive heat from the burning in the test; and that the test period with permitted integrity and insulation could be extended from 6 minutes to 100 minutes. It was noted that the temperature of the glass surface could be kept under $90^{\circ} \mathrm{C}$ for a 100 -minute-test. The substitution of the fireproof glass with water film for the overhead door has been proven workable.
\end{abstract}

KEYWORDS: water film, heat-resistant, fireproof glass, fire test

\section{INTRODUCTION}

In many buildings, such as shopping malls and some special architecture as high atriums, fireproof overhead doors (e.g., iron rolling doors) and fireproof glass are often installed as the entrance doors or as display windows. Large panes of glass also appear in high-technology factory buildings. In Taiwan, new rules of building design and construction [1] have recently been announced, and one stated that the glass used as the door or window of the fireproof compartment should be provided with fire-resistant capability. However, in accordance with UL 10B [2], the width of fireproof overhead door should be less than $3 \mathrm{~m}$ and this restriction gives rise to many problems. For example, if the width of opening for fireproof compartment is over $3 \mathrm{~m}$, approved materials of fireproof overhead door can not be found. In recent years, architects have been looking for new methods, new materials or new designs to replace the overhead door (rolling door) based on the viewpoint of esthetics and the utilization of connected space.

For glass doors or windows setup in public places, the heat insulation (heat-resistant properties) is indispensable especially for life saving in a fire with intensive heat 
radiation or heat convection. In the past, many doors were mostly covered a layer of solid substance to protect them from high-temperature heating. As the solid substance was heated, it would absorb a large amount of latent heat to change its phase, such as melting or sublimation, so that the heat transferred into the protected object would be lower to achieve the goal of heat-protection. Some researches [3-6] used different theoretical or experimental methods to analyze the phase changes for different solids. These studies are useful for the ablative solid material on heat-protection. This protection method was often utilized on the high-speed flight object or a portion of military facilities.

In addition, the applications of liquid for the heat-protection were also common. Thomas and Sunderland [7] and Aihara et al. [8] used the spray method to form a water film on solid surfaces to take away the heat and lower the temperature by evaporation of the water film. Results indicated that the water film had good cooling effects. Chang et al. [9] and Yan $[10,11]$ studied a vertical tube with a layer of water film on the wall and their results showed that the heat transfer mainly resulted from the evaporation of the water film. Some studies [12-14] considered an adiabatic flat plate with a flowing water film on it to be placed in a high-temperature flow field. They used numerical methods to investigate the relations among the factors such as flow temperature, velocity, evaporation and cooling rate. Lin et al. [15] used a pair of parallel flat plates with water film on the surface and a low temperature gas passing through in between to study the mass and heat transfer.

From the above descriptions, the application of the water film could be considered as a good choice for heat-protection or insulation. Water is very easy to obtain and treat, therefore water can be of great help for the industrial application especially in an emergency. When the surrounding temperature is not very high, the total heat transferred onto the water film surface was mainly by convection. However, the physical model is different if the object with the water film directly exposed to a high temperature environment. In a high temperature environment, the heat is not only transferred onto the water film but also into the object, the film is additionally influenced by the radiation and the conduction at the same time. Furthermore, the heat absorption at different position of the water film is different. From the calculation of the Beer's law [16,17], it was found that the quantity of the heat absorption would decrease as the water film goes downstream. Available literatures on the combined effects of convection and radiation on a liquid film is scarce. In this study, an experimental method was designed to investigate the effects of the water film on the heat-resistance property associated with the insulation of a fireproof glass. The latent heat of water could be used to protect the glass from melting or breaking as a fire occurs. And therefore the fire or smoke would not propagate to the neighboring space to cause more property and personal damage.

\section{EXPERIMENTAL APPARATUS AND METHODS}

In this study, a multi-function refractory furnace and a water supply system were used to perform the experiment, which included room-temperature tests and fire tests.

\section{Multi-function Refractory Furnace}

Figure 1 shows the sketch and direct photographs of the multi-function refractory furnace which is used for horizontal and vertical fire tests. For horizontal fire test, the specimen such as small-scale fire doors or glass windows can be set on the front of the furnace. For vertical fire test, the specimen such as columns or cables can also be set on the top of the furnace for through-penetration test. There are two burners and three thermocouples on 
both sides of the furnace, as shown by the interior view of the furnace in Fig. 1 . The locations of thermocouples are determined according to the test modes. Considering the combustion system, because the burners are located at both sides of the furnace, the flow circulation would occur to enhance the mixing and heat transfer of the hot gas inside of the furnace and further to produce uniform temperature distribution for the fire test. The flame type of the burner is the yellow-color jet-diffusion flame with strong thermal radiation. The main fuel used is diesel fuel and LPG is only used as the auxiliary fuel to ignite the burner. Natural convection method is adopted for the exhaust system and a damper is installed on the exhaust pipe to control the flow rate to maintain a stable pressure condition inside the furnace.

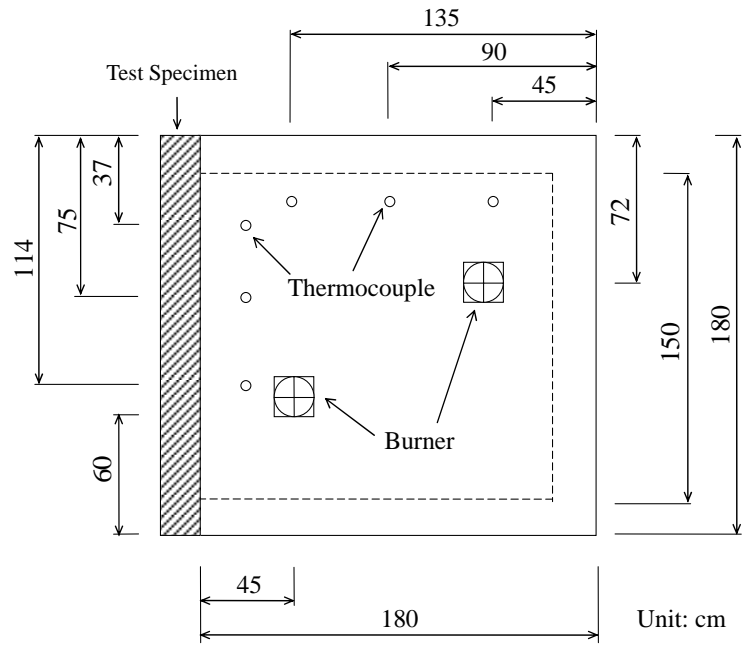

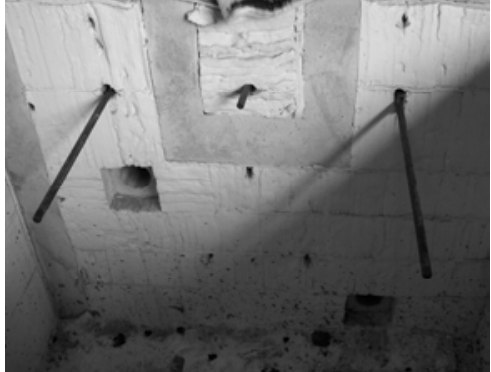

Interior View

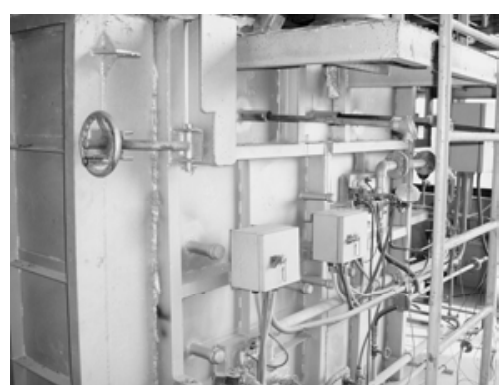

Side View

Fig. 1. The sketch and direct photographs of the multi-function refractory furnace.

\section{Water Supply System}

The water supply system included a hydraulic pump, spray nozzles and the piping. According to the initial tests of various spray patterns for different nozzles, flat spray nozzle was found to be more suitable for our study. Thus, two types of flat spray nozzles were selected to perform the experiment, denoted by Type A and Type B. The maximum usable spray angle and flow rate for two types of nozzles are $65^{\circ}, 76.7 \mathrm{~cm}^{3} / \mathrm{s}$ and $95^{\circ}$, $266.7 \mathrm{~cm}^{3} / \mathrm{s}$, respectively. According to the specifications of the nozzles, the pump used 
in the experiment was a Grundfos single-phase $220 \mathrm{~V}-2210 \mathrm{~W}$ pump, which had the maximum head $52 \mathrm{~m}$ and the flow rate of $2766.7 \mathrm{~cm}^{3} / \mathrm{s}$. The operation temperature of the working fluid for the pump are $0 \sim 90^{\circ} \mathrm{C}$. The operating pressure $\mathrm{P}$ in our experiment was varied from $0 \mathrm{kPa}$ to $200 \mathrm{kPa}$.

At the beginning, the room-temperature experiment was conducted to investigate the spray patterns of single nozzles and multi-nozzles. The whole apparatus consisted of the water supply system described above, a water tank and a tempered glass with a set of support frame. In the experiment, the water spray was impinged onto the top part of the tempered glass to produce a water film flowing downward. The water flowing down was collected into the water trough with a drain pipe at the side. The dimensions of the tempered glass and the water trough were $130 \mathrm{~mm}$ x $130 \mathrm{~mm}$ x $10 \mathrm{~mm}$ and $1500 \mathrm{~mm}$ x $100 \mathrm{~mm}$ x $100 \mathrm{~mm}$, respectively.

\section{ROOM-TEMPERATURE TESTS}

\section{Single-nozzle Tests}

To obtain a water film, it is very important to understand the spray patterns under various conditions. Figure 2 shows the parameters defined for a vertical spray and an oblique spray. Considering a spray injected vertically downward shown by Fig. 2a, $\theta$ is defined as the spray angle, and $L_{B}$ is defined as the breakup length, which means the maximum length of the liquid sheet. From the observations, it was found that spray angle $(\theta)$ increases with the increase of inlet pressure, and at operating pressure $\mathrm{P}=150 \mathrm{kPa}$, the spray angle of Type A and Type B attains the maximum angle $65^{\circ}$ and $95^{\circ}$ respectively; and will not change as operating pressure continuously raised to $200 \mathrm{kPa}$. The breakup length $\left(\mathrm{L}_{\mathrm{B}}\right)$ was gradually shorten and the water sheet became visually unapparent as pressure increased. The reason is easily understood. As operating pressure increases, the effect of atomization is much better and then enhances the droplets break up from the liquid sheet. Thus, the area of the liquid sheet and the breakup length would decrease.

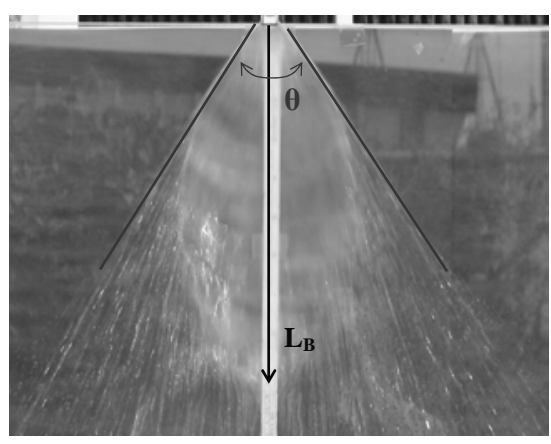

(a)

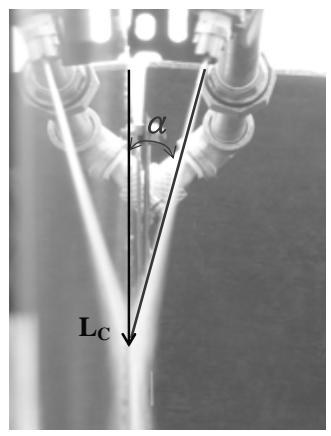

(b)

Fig. 2. Parameters defined for (a) a vertical spray and (b) an oblique spray.

Figure $2 \mathrm{~b}$ shows that an oblique spray injected downward and impinged onto a vertically-aligned tempered glass with an injection angle $(\alpha)$. The vertical distance between the nozzle outlet and the contact point of impingement is defined as the contact length $L_{C}$. From the front view, the contact point is basically a strip. The left part of the photograph Fig. $2 \mathrm{~b}$ is the image of the oblique spray reflected by the glass. In the experiment, the end point of the water sheet was chosen as the contact point. Thus, the 
contact length could be assumed $\mathrm{L}_{\mathrm{C}} \sim \mathrm{L}_{\mathrm{B}} \cos \alpha$. From the observations, it was shown that as operating pressure $\mathrm{P}$ increases, the injection angle $\alpha$ must be increased due to the decrease of the breakup length $L_{B}$ and thus leads to the reduction of the contact length $L_{C}$. After several tests, we found that injection angle $\alpha$ has much influence on the extent of the spatters, i.e., water drops jumping off the glass. We also noticed that as large as the contact strip is located within the area of the water sheet, the extent of the spatters would be lowered. Therefore, on the premise of reducing the spatters and making the water adhere to the glass to form a uniform water film, the determination of the injection angle $\alpha$ is very important. After series of tests, it was found that as the nozzle is closer to the glass ( $\alpha \sim 10^{\circ}$ and $\mathrm{L}_{\mathrm{C}} \sim 4.5 \mathrm{~cm}$ ), the extent of the spatters can be minimized.

\section{Multi-nozzles Tests}

Based on the above single-nozzle tests, one realized that the operating pressure and injection angle $\alpha$ are very important for the formation of the water film and the reduction of the spatters. Thus, $\alpha \sim 10^{\circ}$ and $\mathrm{L}_{\mathrm{C}} \sim 4.5 \mathrm{~cm}$ were used to be the optimum value to move on to the multi-nozzles tests. The selection of the separation distance between each nozzle is very important. If the separation distance is too large, a portion of the glass area would not contain water film. But if the separation distance is too small, a column of water at the boundary of two neighboring sprays would appear and cause the film to become inhomogeneous. From several tests, the separation distance of $20 \mathrm{~cm}$ and five nozzles were determined for the tested glass with $130 \mathrm{~mm}$ width, and the set up for each nozzle was selected as before $\alpha \sim 10^{\circ}$ and $\mathrm{L}_{\mathrm{C}} \sim 4.5 \mathrm{~cm}$. The increase of the amount of the water spray usually enhances water spatters particularly on the upper part of the water film. The water spatters might cause a grave damage to the interior of the refractory furnace, therefore, a buffer box set on the top of the test frame was designed to block and collect the spatters in the fire tests.

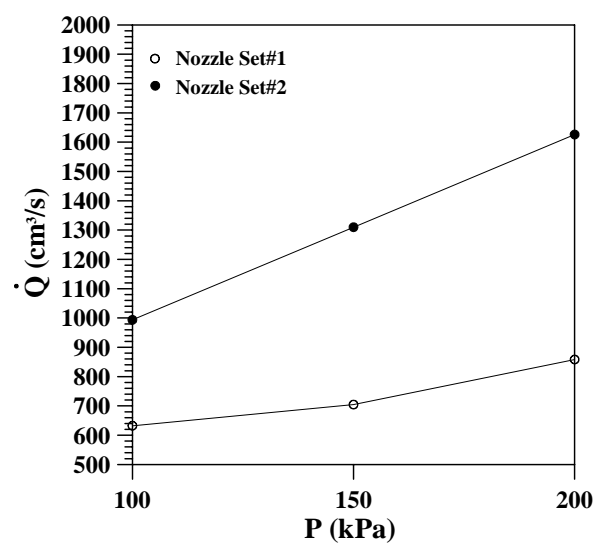

Fig. 3. Variations of flow rate versus operating pressure for two nozzle sets.

To further assure the thickness and the uniform distribution of the water film, four adjustable auxiliary nozzles were added. Thus, Nozzle Set \#1 (including five Type A nozzles and four adjustable auxiliary nozzles) and Nozzle Set \#2 (including five Type B nozzles and four adjustable auxiliary nozzles) were built up to perform the tests. Figure 3 shows the variations of flow rate versus operating pressure for the two nozzle sets. From the results, it could be found that as operating pressure is increased from $100 \mathrm{kPa}$ to 200 
$\mathrm{kPa}$, the flow rates for the two nozzle sets are varied from 630 to $870 \mathrm{~cm}^{3} / \mathrm{s}$ and 990 to $1660 \mathrm{~cm}^{3} / \mathrm{s}$, respectively. Nozzle Set $\# 2$ had larger flow rate than Nozzle Set $\# 1$. The difference of the flow rate between two nozzle sets was enlarged as the operating pressure increased, as shown in Fig. 3.

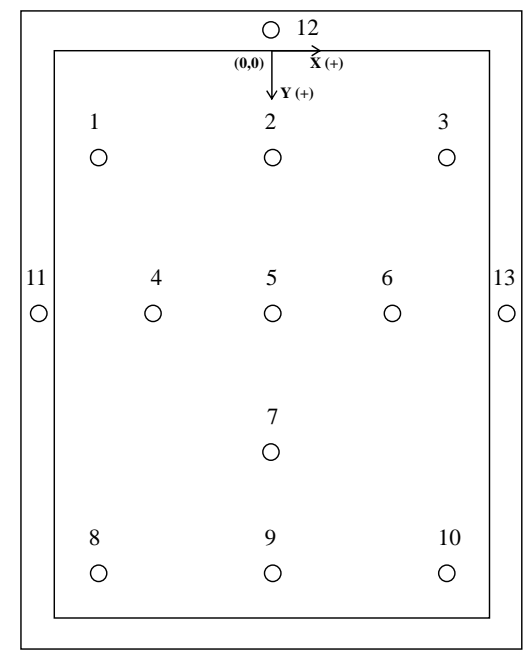

Fig. 4. Measuring positions for the thickness of the water film and locations of thermocouples on the glass and frame surfaces.
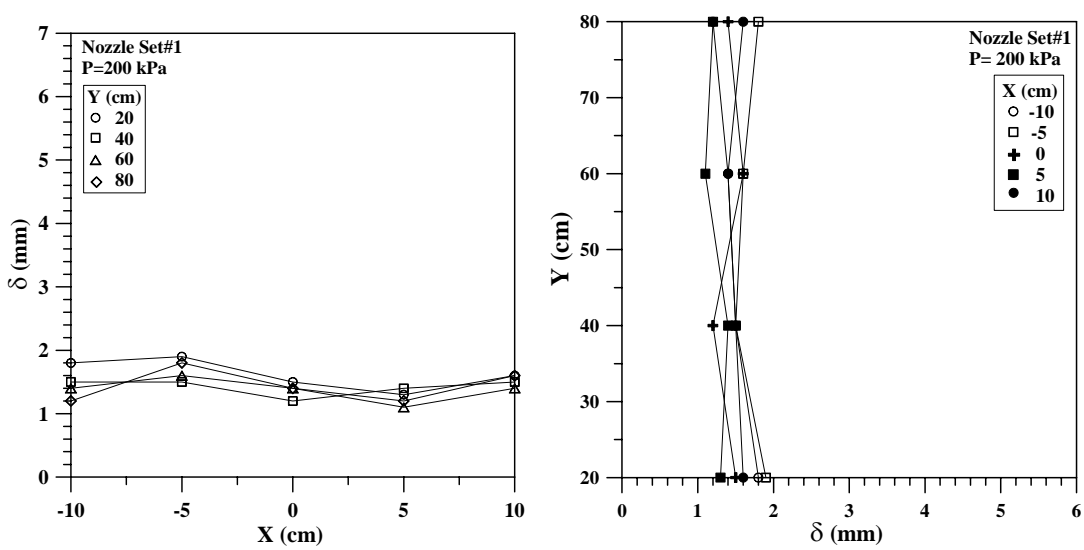

Fig. 5. Variations of the thickness of the water film for the Nozzle Set \#1, P=200 kPa.

After establishing the most appropriate apparatus and determining the proper operating mode, we measured the thickness of the water film on the glass. Because the distribution of the water film for the whole glass was quite uniform and similar, only one region of the water film was chosen to measure the thickness. The measuring positions are specified by Fig. 4, taken the rightward and the downward of the origin to be the $+\mathrm{X}$-axis and $+Y$-axis, respectively. Figure 5 shows the variations of the thickness of the water film versus the measuring positions for the Nozzle Set $\# 1$ under $\mathrm{P}=200 \mathrm{kPa}$. The results showed that for a fixed Y position, the thicknesses are varied between $1.2 \mathrm{~mm}$ and 1.8 $\mathrm{mm}$ and the film has nearly uniform distributions along the horizontal direction. 
Considering the variations of thickness along the vertical direction (a fixed $\mathrm{X}$ position), it was found that as Y position goes from $20 \mathrm{~cm}$ to $80 \mathrm{~cm}$, the thickness of the water film first decreases a little and thereafter increases. This phenomenon is caused by the flow deceleration and the accumulation effect in the downstream due to the surface resistance of the glass; and this phenomenon would be more obvious as the length of the glass increases. Besides, it was also found that the thickness at the position closer to the outlet of the nozzle has the maximum value. The thickness of the water film generated by using the Nozzle Set \#2 was also measured. From these tests, it was noted that Nozzle Set \#1 has more uniform distribution of water film and uses less water. Thus, we chose Nozzle Set \#1 to further perform the practical fire test.

\section{FIRE TESTS}

\section{Fire Test for Fireproof Glass without Water Film}

Before the fire test of the fireproof glass with water film, a comparative experiment using a dry fireproof glass was firstly carried out and analyzed to determine some basic characteristics, such as surface temperatures corresponding to the insulation of the glass. In the fire tests, the interior temperature distribution of the refractory furnace was controlled according to the temperature curve prescribed by CNS 14815 [18]. The fireproof glass used in the experiment was FIRELITE made by the Nippon Electric Glass.
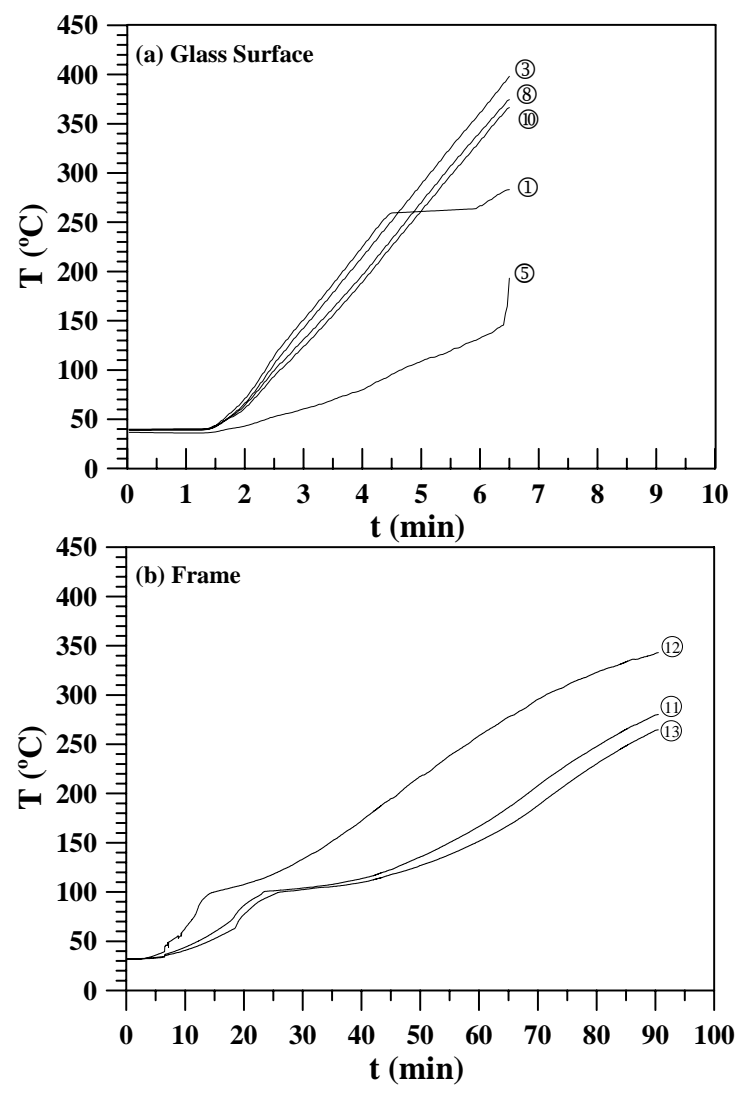

Fig. 6. Temperature variations on the glass and frame surfaces without water film. 
The glass is clear and wireless. It can withstand the thermal shock of cold water used in fire fighting but has no heat insulation. The thickness of the fireproof glass was about $0.5 \mathrm{~cm}$ and the fire test period for this glass could reach one hour with permitted integrity. In the test, the glass was fixed by an iron frame, which was fitted onto the test frame with concrete. Refractory silicone was filled between the glass and the frame to avoid smoke leakage and the K-type thermocouples were also placed on the front side of the glass.

In Fig. 4, besides the coordinates for measuring the thickness of the water film, it also shows the locations of thermocouples on the fireproof glass and frame surfaces. In the dry test, only points of $1,3,5,8,10,11,12$ and 13 were used to measure the actual temperature variations. Figure 6 shows the temperature variations on the glass and frame surfaces without water film in the fire test. Variations of the gas temperatures in the interior of the furnace for the tests without and with water film are reported in Fig. 7. The curves denoted by a, b, c and Ave. respectively represent the gas temperatures measured by thermocouples located with a distance of $35 \mathrm{~cm}$ from the glass surface in the top, middle and bottom sections of the furnace, and their averaged values. From the Fig. 7, it is found that all the curves of a, b, c and Ave. for the test without water film closely followed the temperature curve prescribed by CNS 14815, and showed the uniform temperature distribution inside of the furnace.

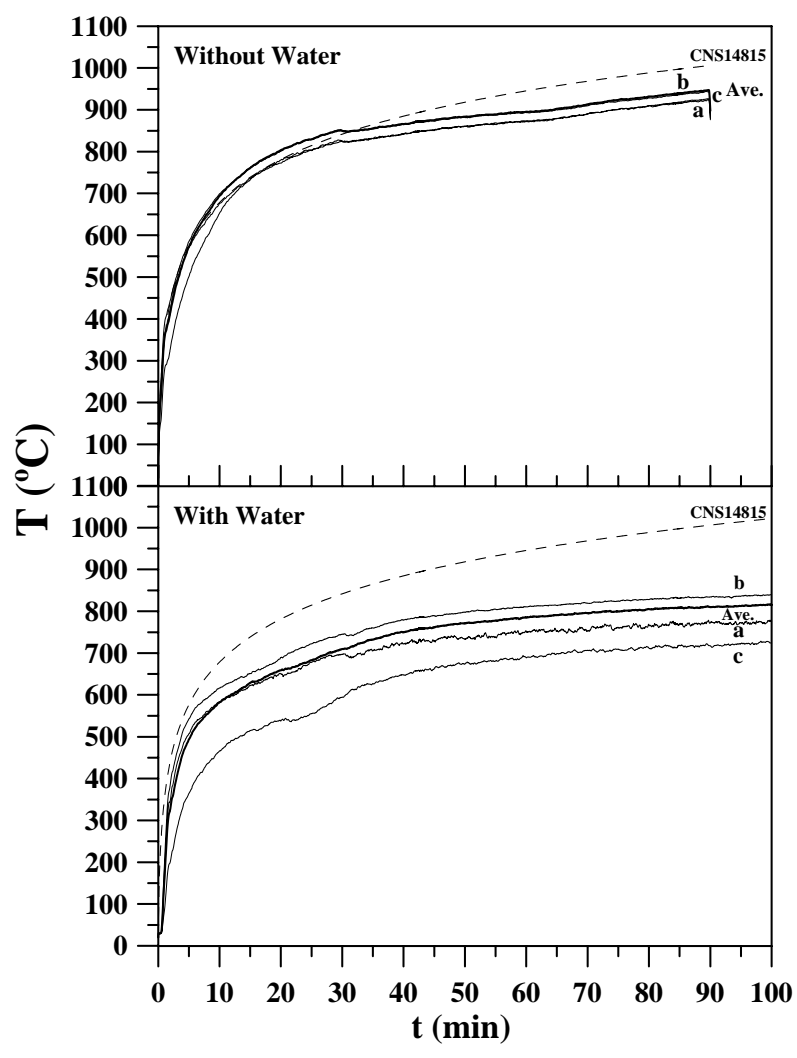

Fig. 7. Variations of the gas temperatures in the interior of the furnace in the tests. 
In view of Figs. 6 and 7, it is found that after 6 minutes firing, the temperatures in the interior of the furnace increased to $600^{\circ} \mathrm{C}$ approximately, however, all the temperatures on glass surface (points of $1,3,5,8$ and 10 ) almost exceeded $210^{\circ} \mathrm{C}$; and that the thermocouples all came off from the glass surface resulting in no records after 6 minutes. In the test, thermal radiation penetrated through the glass was quite strong; and even at a distance of $2 \mathrm{~m}$ away from the front side of the glass, the intensive radiation could also be felt. This indicates that the heat transfer rate through the glass is very strong. In the whole experiment process, crack did not appear on the glass surface but the silicone between the glass and the frame was burnt and the smoke escaped. Under these circumstances, one could realize that the fireproof glass just can maintain its integrity to avoid cracks and fissures but does not possess heat insulation.

The temperature variations on the frame surface did not increase as fast as the glass surface mainly due to the concrete filled around the frame. After 60 minutes, the temperature of upper frame (point of 12) was over $210^{\circ} \mathrm{C}$ and the temperatures on the both sides of the frame (points of 11 and 13) were lower than $210^{\circ} \mathrm{C}$ until 80 minutes because of the smoke and hot air flowing upward. After this test, it was realized that although the fireproof glass did not break to let smoke flowing out, it did not offer much resistance to heat transfer because its surface temperature exceeded $210^{\circ} \mathrm{C}$ in just a few minutes.

\section{Fire Test for Fireproof Glass with Water Film}

A new test frame was redesigned and fabricated to satisfy the experiment conditions for the fire test on the water-film-covered fireproof glass. The size of the test frame was different from the standard one that the depth was extended outward from $20 \mathrm{~cm}$ to $40 \mathrm{~cm}$ to prevent the spatters. The main parts of the test frame consisted of the buffer box, the water tank, vents and drain pipes. During the fire test, Nozzle Set \#1 was used and the injection angle and the contact length were arranged the same before $\left(\alpha \sim 10^{\circ}\right.$ and $\mathrm{L}_{\mathrm{C}} \sim$ $4.5 \mathrm{~cm}$ ). The interval between the glass and the frame was similarly filled with refractory and water-resistant silicone to prevent the leakage of smoke and water. From the observation of the experiment, it was found that in the whole process the glass surface seemed to remain the same and the silicone was not burnt and the smoke was not seen; and that the tested glass showed good integrity. Figure 8 shows the temperature variations on the glass and frame surfaces with water film. Figure 8 is divided into three subfigures respectively showing the surface temperatures of the upper (points of 1, 2, and 3) and lower (points of 4 to 10) parts of the glass, and the surface temperatures of the frame (points of 11, 12 and 13).

Results showed that the average upper surface temperature (points of 1,2 , and 3 ) of the fireproof glass increased from $29^{\circ} \mathrm{C}$ to $35^{\circ} \mathrm{C}$ and the increment of temperature in this region was the minimum. The reason is that the positions of the thermocouples were very close to the contact point of the water spray and the water film thickness here was the maximum, therefore the heat could be taken away rapidly. As for the lower region of the glass, the maximum temperature for the whole process was about $87^{\circ} \mathrm{C}$. Taking the vertically-aligned points of 2, 5, 7 and 9 into comparisons, it could be found that from the top (point of 2) to the bottom (point of 9), the maximum temperature increased from $34^{\circ} \mathrm{C}$ to $87^{\circ} \mathrm{C}$ approximately. This indicates that the thickness of the water film gradually reduces resulting from the heat transfer and water evaporation. As for the horizontal-aligned points of 4, 5 and 6 (Fig. 4), the temperature variations were very 
similar and the maximum temperature was between $65^{\circ} \mathrm{C} \sim 75^{\circ} \mathrm{C}$. This shows that the distribution of water film was horizontally uniform.

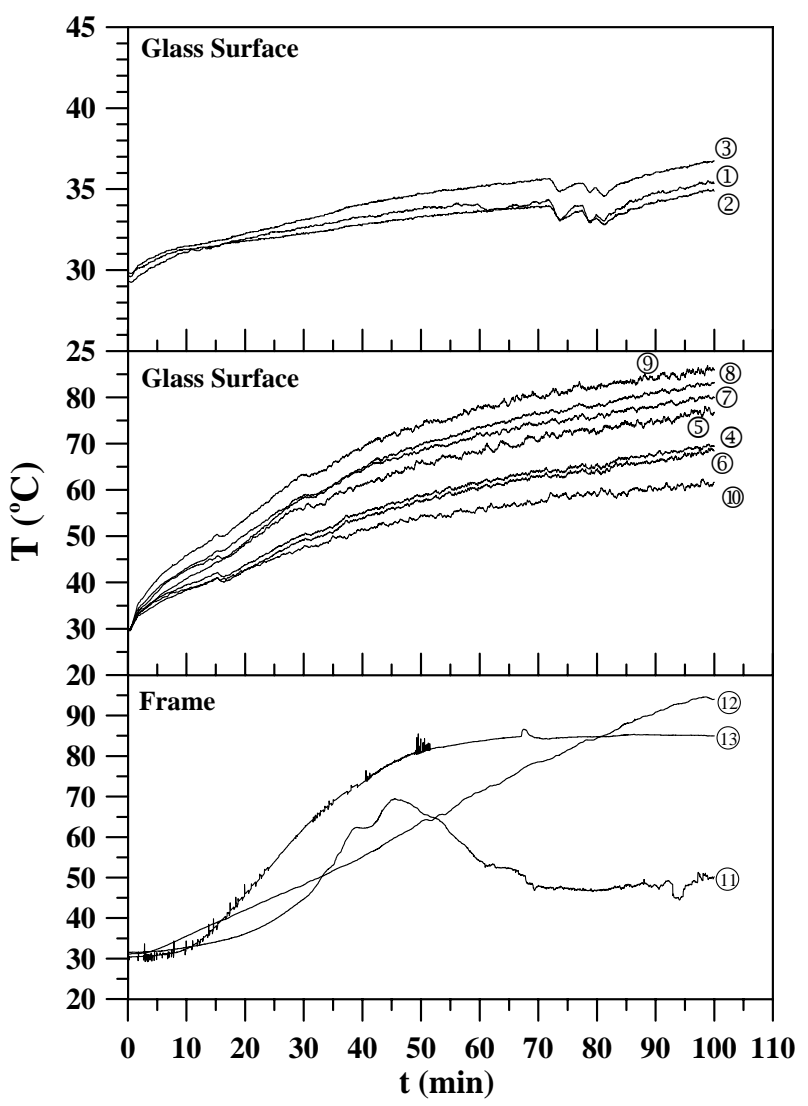

Fig. 8. Temperature variations on the glass and frame surfaces with water film.

Besides, it seems from Fig. 8 that the temperatures of the frame were not too high and the maximum value was around $95^{\circ} \mathrm{C}$. However, it deserves to notice that the sudden drop of the temperature for the point 11 was due to the permeation of the water which came out from the concrete. Concerning the gas temperatures in the interior of the furnace for the fire test with water film, as shown in Fig. 7, it is shown that all the curves of a, b, c and Ave. were lower than the temperature curve prescribed by CNS 14815, because of the heat loss to the water film and the mixing with the water vapor inside of the furnace. From the above experimental results, one may conclude that the application of the water film could improve the heat insulation of the tested fireproof glass especially the resistance of the thermal radiation. And the design could extend the test period with permitted integrity and insulation from the original 6 minutes to 100 minutes.

\section{CONCLUSIONS}

The objective of this study was to investigate the effect of the water film on the heat-resistance property associated with the insulation of a fireproof glass. The evaporative latent heat for the water film was used to protect the fireproof glass from 
melting or breaking in the fire test. The conclusions are made as follows:

(1) The thickness of the water film depends on the operating pressure of the pump and the injection angle of the spray nozzle.

(2) By using a properly chosen nozzle set with a buffer box, a uniform water film with low spatters can be generated on the glass surface for the fire test.

(3) The water film could effectively resist the intensive thermal radiation in the fire test and the test period with permitted integrity and insulation could be extended from 6 minutes to at least 100 minutes. The temperature of the glass surface could be controlled under $90^{\circ} \mathrm{C}$ for a 100 -minute-test.

(4) The substitution of fireproof glass with water film to the overhead door has been proven workable.

\section{REFERENCES}

[1] Technological Codes of the Building, "79th Item of Building Design and Construction,” Taiwan, ROC, 2004.

[2] UL 10B, "Standard for Fire Tests of Door Assemblies," Underwriter Laboratory Standards, 2001.

[3] Landau, H.G., "Heat Conduction in a Melting Solid," Quarterly Applied Math, 8, pp. 312-319, (1950).

[4] Carslaw, H.S., and Jaeger, J.C., Conduction of Heat in Solid, Oxford University Press, UK, 1959, p. 510.

[5] Sunderland, T.E., and Grosh, R.J., "Transient Temperature in a Melting Solid,” J. Heat Transfer, 83, pp. 409-419, (1961).

[6] Zien, T.F., "Integral Solution of Ablation Problems with Time-dependent Heat Flux,” AIAA J., 16, pp. 1287-1295, (1978).

[7] Thomas, W.C., and Sunderland, J.E., "Heat Transfer Between a Plane Surface and Air Containing Suspended Water Droplet,” Ind. Eng. Chem. Fundam., 9, pp. 369-374, (1970).

[8] Aihara, T., Taga, M., and Haraguchi, T., "Heat Transfer from a Uniform Heat Flux Wedge in Air-water Mist Flows," Int. J. Heat Mass Transfer, 22, pp. 51-60, (1979).

[9] Chang, C.J., Lin, T.F., and Yan, W.M., "Natural Convection Flows in a Vertical Open Tube Resulting from Combined Buoyancy Effects of Thermal and Mass Diffusion,” Int. J. Heat Mass Transfer, 29, pp. 1543-1552, (1986).

[10] Yan, W.M., "Liquid Film Vaporization on Natural Convection Heat and Mass Transfer in a Vertical Tube,” The Canadian Journal of Chemical Engineering, 70, pp. 452-462, (1992).

[11] Yan, W.M., "Binary Diffusion and Heat Transfer in Mixed Convection Pipe Flows with Film Evaporation," Int. J. Heat Mass Transfer, 36, pp. 2115-2123, (1993).

[12] Shembarker, T.R., and Pai, B.R., "Prediction of Film Cooling with a Liquid Coolant,” Int. J. Heat Mass Transfer, 29, pp. 899-908, (1986). 
[13] Yan, W.M., and Soong, C.Y., "Numerical Study of Liquid Film Cooling in a Turbulent Gas Stream,” Int. J. Heat Mass Transfer, 36, pp. 3877-3886, (1993).

[14] Yan, W.M., "Convective Heat and Mass Transfer from a Falling Film to a Laminar Gas Stream,” Warme-und Stoffubertragung, 29, pp. 79-87, (1993).

[15] Lin, T.F., Chang, C.J., and Yan, W.M., "Analysis of Combined Buoyancy Effects of Thermal and Mass Diffusion on Laminar Forced Convection Heat Transfer in a Vertical Tube,” J. Heat Transfer, 110, pp. 337-344, (1988).

[16] Curico, T.A., and Petty, C.C., "The Near Infrared Absorption Spectrum of Liquid Water,” J. Opt. Soc. Amer., 41, pp. 302-304, (1951).

[17] Plyler, E.K., and Acquista, N., "Infrared Absorption of Liquid Water from 2 to 42 Microns," J. Opt. Soc. Amer., 44, pp. 505-507, (1954).

[18] CNS 14815, "Method of Fire Resistance Test for Fire Fixed Window of Buildings,” Chinese National Standards, Taiwan, ROC, 2004. 